\title{
Value-based design for the elderly: An application in the field of mobility aids
}

\author{
Simone T. Boerema MSc, Lex van Velsen PhD, Miriam M. R. Vollenbroek- \\ Hutten Prof \& Hermie J. Hermens Prof
}

To cite this article: Simone T. Boerema MSc, Lex van Velsen PhD, Miriam M. R. VollenbroekHutten Prof \& Hermie J. Hermens Prof (2016): Value-based design for the elderly: An application in the field of mobility aids, Assistive Technology, DOI: 10.1080/10400435.2016.1208303

To link to this article: http://dx.doi.org/10.1080/10400435.2016.1208303

View supplementary material $₫$

\begin{tabular}{l} 
Accepted author version posted online: 17 \\
Aug 2016. \\
Published online: 17 Aug 2016. \\
\hline
\end{tabular}

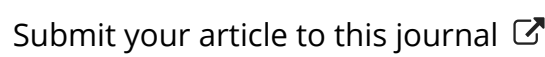

山 Article views: 80

a

View related articles

View Crossmark data \lceil 


\title{
Value-based design for the elderly: An application in the field of mobility aids
}

\author{
Simone T. Boerema, MSc (10,b, Lex van Velsen, PhD (1) ${ }^{a, b}$, Miriam M. R. Vollenbroek-Hutten, Prof $\mathbb{(}^{a, b}$, \\ and Hermie J. Hermens, Prof ${ }^{a, b}$ \\ aTelemedicine Group, Roessingh Research and Development, Roessingsbleekweg, Enschede, The Netherlands; ${ }^{\text {b}}$ Telemedicine Group, Faculty of
Electrical Engineering, Mathematics and Computer Science, University of Twente, Drienerlolaan, Enschede, The Netherlands
}

\begin{abstract}
In the aging society, the need for the elderly to remain mobile and independent is higher than ever. However, many aids supporting mobility often fail to target real needs and lack acceptance. The aim of this study is to demonstrate how value-based design can contribute to the design of mobility aids that address real needs and thus, lead to high acceptance. We elicited values, facilitators, and barriers of mobility of older adults via ten in-depth interviews. Next, we held co-creation sessions, resulting in several designs of innovative mobility aids, which were evaluated for acceptance via nine in-depth interviews. The interviews resulted in a myriad of key values, such as "independence from family" and "doing their own groceries." Design sessions resulted in three designs for a wheeled walker. Their acceptance was rather low. Current mobility device users were more eager to accept the designs than non-users. The value-based approach offers designers a close look into the lives of the elderly, thereby opening up a wide range of innovation possibilities that better fit their actual needs. Product service systems seem to be a promising focus for targeting human needs in mobility device design.
\end{abstract}

\section{ARTICLE HISTORY}

Accepted 24 June 2016

\section{KEYWORDS}

acceptance; assessment; mind maps; mobility; older adults; usefulness; values; wheeled mobility aids

\section{Introduction}

Society is aging and the need for the elderly to remain independent is higher than ever. In the Netherlands, the population of 65 years and older will increase from 2.5 million in 2010 to 4 million elderly in 2030-This works out to about one in four inhabitants (Van Campen, 2011). Of this elderly population in 2030, it is expected that 1 million are frail elderly of which two thirds are living solitary (Van Campen, Den Draak, \& Ras, 2011). To keep the costs for society manageable, supporting these elderly in their independence is very important. This can be done by supporting their mobility as described by Satariano et al. (2012), who emphasized that optimal mobility is a key component of healthy aging and that mobility relates to all facets of daily life:

Mobility refers to movement in all of its forms, including basic ambulation, transferring from a bed to a chair, walking for leisure and the completion of daily tasks, engaging in activities associated with work and play, exercising, driving a car, and using various forms of public transport. (p. 1508)

Reasons for using mobility aids, related to functional impairments, are often a need and desire to continue to be active and to continue performing everyday activities, including the potential to take part in social activities (Hedberg-Kristensson, Ivanoff, \& Iwarsson, 2007). La Grow, Yeung, Towers, Alpass, and Stephens (2013) showed that mobility was directly related to quality of life and this relation was mediated by the satisfaction with functional capacity. The individual desire to be mobile is therefore expected to vary extensively between individuals, and to depend on personal needs, values, and the environment.
A study among Dutch, community-dwelling 85-year-olds concluded that the presence and use of assistive devices (including mobility aids) could be improved upon (De Craen, Westendorp, Willems, Buskens, \& Gussekloo, 2006): A large group of elderly lacks the device they need, does not use them when they are available, or does not accept assistive aids when they were offered to them. Hirsch et al. (2000) stated that assistive technology (including technology for mobility) is often underused or used erroneously, due to a mismatch between design and the context of use. They (and others, e.g., Häggblom-Kronlöf \& Sonn, 2007, and McMillen \& Söderberg, 2002) suggested that designers should "immerse" themselves into the lives of elderly to fully understand their needs on a functional, emotional, and social level. This immersion, and the subsequent translation of findings into product design, is often typed as user- or human-centered design. In this design approach, it is advocated to consult potential end-users as early as possible in the design process, and to involve them continuously (Gould \& Lewis, 1985), as (potential) end-users have been found to supply critical contextual information to the design team, that can consequently translate this into product innovations (Kujala, 2003). Recently, the concept of value-based design originated in business science (Kim \& Mauborgne, 2004) and has merged with the human-centered design approach. Value-based design focuses on eliciting the most important values a person has in life, and to cater for these values. As such, value-based design can be considered to be an extension of human-centered design. Where human-centered design is mainly "artefact-centered" and focused on identifying product features that are desired by (potential) end-users, value-based design aims to create useworthy design

CONTACT Simone T. Boerema, MSc s.boerema@rrd.nl ETelemedicine Group, Roessingh Research and Development, Roessinghsbleekweg 33b, 7522 AH, Enschede, The Netherlands.

Color versions of one or more of the figures in the article can be found online at www.tandfonline.com/UATY.

(c) 2016 RESNA 
that caters for a person's values in life (Cockton, 2005). Values have been defined as "ideals or interests a (future) end user aspires to or has" (Van Velsen, Wentzel, \& Van Gemert-Pijnen, 2013). For example, a value for parents can be that their children can grow up safely, and their actions in life will be motivated by this value. Value-based design can be considered a way in which user values and the factors that motivate them to use a specific product are elicited, analyzed, and mapped within a human-centered design process (which also includes activities such as testing the acceptance and usability of a new service or product; Bolchini, Garzotto, \& Paolini, 2008; Kujala \& Väänänen-Vainio-Mattila, 2009). Recently, value-based design has also been applied to the design of health interventions (e.g., Van Velsen, Beaujean, Wentzel, Van Steenbergen, \& Van Gemert-Pijnen, 2015) and social services (Wildevuur et al., 2013).

The premise behind value-centered design is that its strong focus on human values, on top of the fulfillment of their explicit needs as a result of the application of a humancentered design focus, results in a design that is both useful as well as elusive (Cockton, 2005). Value-based design can therefore be considered a means to prevent product from failing when it is not accepted while fulfilling the potential end-users' needs after applying a human-centered design focus, an occurrence we have seen often among mobility devices (Bright \& Coventry, 2013). Nonetheless, many factors have been identified to explain this phenomenon, such as financing, as well as more person-based barriers regarding attitudes and beliefs (Gitlin, 1995; McMillen \& Söderberg, 2002; Resnik, Allen, Isenstadt, Wasserman, \& Iezzoni, 2009), such as a personal unwillingness to display dependence on mobility aids (Hedberg-Kristensson et al., 2007). Therefore, besides identifying and designing for end-user values, a strong focus on determining why a specific (prototypical) mobility device is accepted or not during the design process is crucial (Gitlin, 1995; Hedberg-Kristensson et al., 2007). Two of the most critical factors that explain this acceptance include coping style and subjective norm (Ajzen, 1991). Coping style determines for an important part how one acts in times of difficult situations (e.g., not being able to walk as well as one used to) and how one goes about solving this situation (Lazarus \& Folkman, 1984). This can have a great impact on how an elderly person makes a decision to use a mobility device (or not). Subjective norm is "the perceived social pressure to perform or not to perform the behaviour" in question (Ajzen, 1991, p. 188).

In this article, we aim to demonstrate how value-based design can contribute to the design of mobility aids that address real human needs and thus, lead to high acceptance. We will do so by discussing the application of a humancentered, value-based design approach for the creation of innovative products and services that aim to increase the mobility of solitary-living, community-dwelling elderly. This process consists of in-depth interviews with elderly persons to elicit their values in life, followed by the activities we undertook in creating initial designs: a brainstorm and a first selection of ideas. Using in-depth interviews with the elderly with the focus on device acceptance, three prototypes will be presented. We conclude this article with a discussion in which we will set out how future design projects can benefit from our experiences, and how designers should deal with acceptance issues for mobility aids for the elderly.

\section{Mapping elderly values}

The first step in our design process consisted of eliciting individual values of solitary-living, community-dwelling elderly. Therefore, we conducted in-depth interviews, as this method allows for a good exploration of what is important for an individual concerning health-related matters (Britten, 2006).

\section{Methods}

\section{Participants}

Ten aging individuals who need, or may need to, use mobility aids in the near future to sustain daily activities were recruited via a professional homecare organization in the Netherlands. Inclusion criteria were: solitary-living, community-dwelling older adults with minimum age of 70 who receive a small volume of personal and medical homecare of maximally 9 hours per week, without cognitive or communicative disabilities that could hamper the interview.

\section{Data collection}

A semi-structured interview guide with open-ended questions was constructed, focusing on personal values with a focus on current physical activity and mobility aids (Appendix 1). The interviews were conducted at the interviewees' homes. Values were elicited by asking an interviewee about their hobbies and what gives them energy. To identify a value, we asked the interviewees where, how, how often, and with whom they carry out each hobby or activity that gives them energy and that they mentioned. Next, we asked them whether or not this has become more troublesome than it used to be, due to recent functional decline. Additionally, we asked them what (kind of) things they want to do, but cannot (anymore) due to health problems (in other words, the values they aspire to). Then, we questioned the interviewee how they travelled about, to what goal, how often, and with who. And we asked the interviewee to list the mobility aids they used, asked about adaptations to their house, and how the decision is made whether or not to start using a mobility device. These last two questions were asked in order to map the interviewees' mobility situation. Finally, we asked whether or not the interviewee used technology (e.g., the Internet, a mobile phone) and for what goal(s). Current physical activity was assessed by the Physical Activity Scale for the Elderly (PASE) questionnaire (Washburn, Smith, Jette, \& Janney, 1993). The instructions for use given in the PASE Administration and Scoring Manual were followed (http://www.neri.org). The PASE addresses leisure-time, household, and work-related physical activity.

\section{Data analysis}

The interviews were transcribed and translated into a mind map per participant. This visualization form was chosen as it provides a good snapshot of what an interviewee experiences as important in life, and allows for easy sharing of results with 
others (Wheeldon \& Faubert, 2009). Each item on the mind map was determined by means of inductive thematic analysis (Braun \& Clarke, 2006) performed by two coders. First, the coders familiarized themselves with the data. Next, each interview section that concerned a value, attribute, facilitator, or inhibitor was marked as such and provided with a code. For example, family and doing things with others were mentioned as things people like to do (and thus, were coded as attributes); the value social interaction was linked to these two (and other) attributes. Finally, specific issues that contribute to or hinder attributes such as a taxi service to visit the family was coded as facilitator or barrier. Each time a new value or attribute was deduced from the transcriptions, the values, and attributes that were identified until that point in time were reconsidered. As facilitators and inhibitors were very personal, this was not done for these categories. Disagreements on codings were discussed between the coders until agreement was reached. Ultimately, this process led to a mind map that displays a person's values, the attributes that make-up this value (i.e., the activities or wishes that the interviewees mentioned), and the facilitators and inhibitors that play a role for each attribute.

The PASE was scored according to the instructions in the PASE Administration and Scoring Manual (http://www. neri.org). The PASE sub scores were computed by multiplying time spent in each activity (hours per day) or participation in an activity (for household-related activities), with empirically derived weightings, and then summarizing all items to a single PASE score, ranging from 0 to 361 , in which a higher score, indicated a higher level of physical activity.

\section{Ethics}

The study was evaluated by the institutional review board (IRB) of Twente, and they determined that the study was exempt from further IRB review according to the principles expressed in the Declaration of Helsinki. However, the participants did receive written and oral information about the study, including: aim of the study, voluntary participation, no risks, confidentiality and anonymity. And participants gave their informed consent for the interview including audio-recording. The same ethics procedure was applied during the evaluation (reported in the third section).

\section{Results}

The 10 interviewees (average age $80.5(\mathrm{SD}=8.1))$ scored low to very low on the physical activity level (average PASE score $40(\mathrm{SD}=13))$. Biking and walking were their main means of transport. Public transport was considered too difficult or impossible to use (too far from the home, difficult route, etc.), and technology use was predominantly restricted to TV, (mobile) phone, and radio; see Table 1.

The 10 resulting mind maps display unique overviews of the interviewees' values, how they live toward fulfilling these values, and what helps and hinders them in striving toward their values (Figure 1). For example, subject 8 explained after asking for hobbies, that she makes postcards and creates dolls from clay. After explaining how these activities are done in a social context and if she often spends time on these hobbies she replies: "Yes, what else should I be doing all day?" This was coded as a facilitator for the attribute "getting through the day" and categorized as contributing to the value "killing time."

The mind maps visualize three levels: values, attributes, and facilitators and barriers. Several values were shared by multiple interviewees: (1) social interaction, (2) independence, (3) relaxation, (4) killing time, and (5) good physical health. An overview of all values shared by the interviewees is given in Table 2 .

The way in which each value was sought after differed per person. For example social interaction consisted for one interviewee of meeting all kinds of people, for another of going on holiday, and for yet another of doing groceries with others. Social interaction was also hampered by a wide range of causes. For example, one participant wanted to mingle with other people, but was afraid for visiting the adult day care facilities around her, as she did not know what to expect. For another subject social interaction was facilitated by means of the voluntary work of "De Zonnebloem," that organizes trips for people with disabilities. Several people designated killing time as something they strived for. They indicated that activities such as doing jigsaw puzzles or creating greeting cards are not experienced as leisure activities, but as means for having something to do.

The attributes (or, activities or wishes that are linked to a value) that we encountered often include: (1) Doing groceries. This was an important aspect of the interviewees' life and served both, remaining independent and social interaction (as groceries were regularly done in a group). (2) Hobbies. A wide range of hobbies was named as an enabler for relaxation, including fishing and walking outside.

Table 1. Description of the participants based on demographics and the PASE scores $(n=10)$.

\begin{tabular}{|c|c|c|c|c|c|c|c|c|c|c|}
\hline Demographic & 1 & 2 & 3 & 4 & 5 & 6 & 7 & 8 & 9 & 10 \\
\hline Gender (M/F) & $\mathrm{F}$ & $\mathrm{F}$ & $\mathrm{F}$ & $M$ & $\mathrm{~F}$ & $\mathrm{~F}$ & $\mathrm{~F}$ & $\mathrm{~F}$ & $\mathrm{~F}$ & $\mathrm{~F}$ \\
\hline Age (years) & 93 & 72 & 84 & 76 & 69 & 89 & 83 & 69 & 87 & 83 \\
\hline PASE score (0-361) & 38 & 73 & 34 & 23 & 52 & 37 & 36 & 45 & 33 & 31 \\
\hline Where they live ${ }^{a}$ & V & V & $\mathrm{C}$ & V & V & C & $\mathrm{C}$ & V & V & $\mathrm{V}$ \\
\hline Transportation means ${ }^{b}$ & $\mathrm{~T}$ & $\mathrm{~EB}^{*}, \mathrm{Cr}^{*}$ & $\mathrm{~EB}, \mathrm{Cr}$ & $\mathrm{EB}, \mathrm{Cr}, \mathrm{Sc}$ & $\mathrm{EB}, \mathrm{Cr}$ & $B^{*}$ & & & & \\
\hline Mobility aids ${ }^{c}$ & Ca, WW & $\mathrm{Ca}^{*}, \mathrm{WW}$ & WW' & WW & WW & WW & Ca, WW & & & \\
\hline Technology use ${ }^{d}$ & & $M P, P C$ & & MP & & & & & & $M P, D$ \\
\hline
\end{tabular}

Notes. ${ }^{\mathrm{a}} \mathrm{C}=$ city, $\mathrm{V}=$ village.

${ }^{\mathrm{b}} \mathrm{B}=$ bike, $\mathrm{EB}=$ e-bike, $\mathrm{Cr}=$ car, $\mathrm{Sc}=$ scootmobile, $\mathrm{PT}=$ public transport, $\mathrm{T}=$ taxi.

${ }^{\mathrm{C}} \mathrm{Ca}=$ cane, $\mathrm{WW}=$ wheeled walker (Rollator).

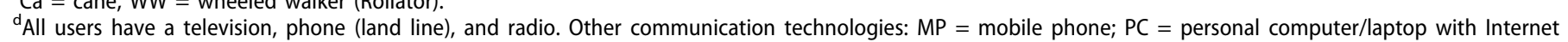
connection, $\mathrm{Tb}=$ tablet, $\mathrm{D}=$ domotics (front door camera, automatic sun blinds).

*Owned but not used. 


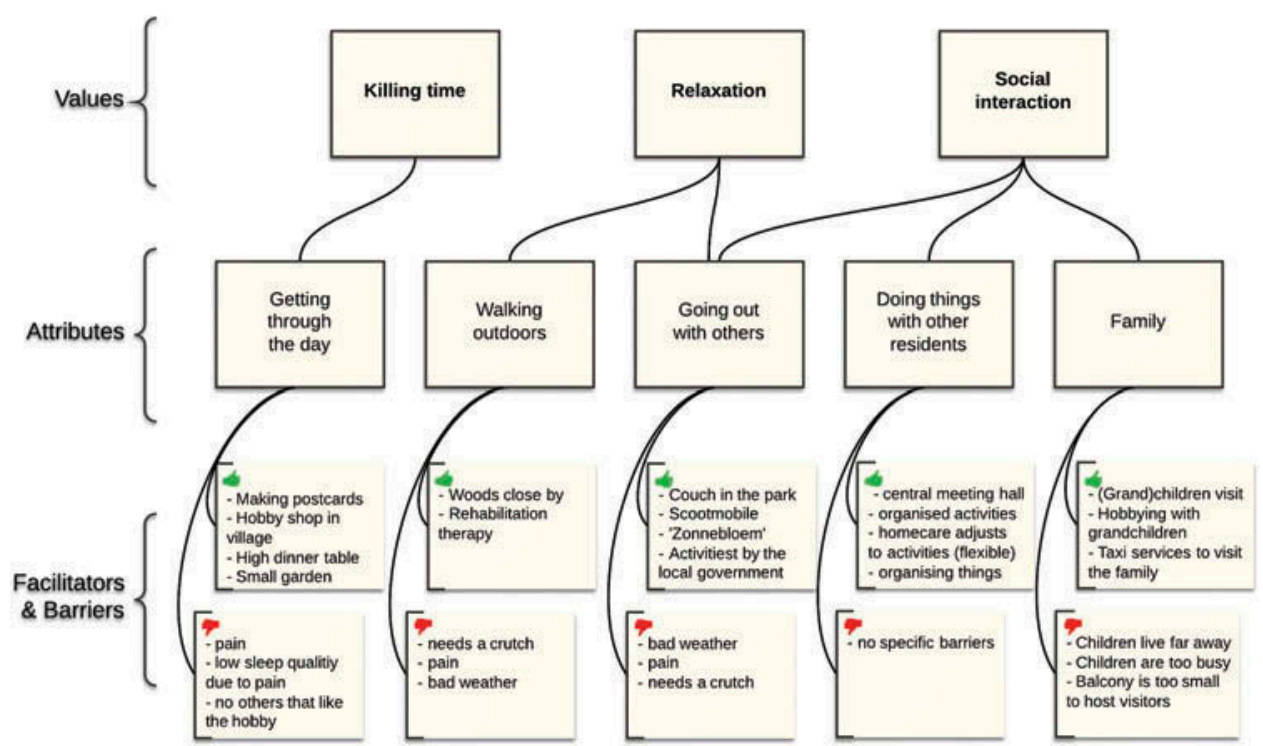

Figure 1. Excerpt of mind map of subject 8 . The three levels indicating the values, attributes, and facilitators and barriers connected by lines indicating their relationships.

Table 2. Overview of values described by the participants $(n=10)$.

\begin{tabular}{lc}
\hline Values & Count \\
\hline Social interaction & 10 \\
Independence & 8 \\
Relaxation & 7 \\
Expanding life space/social world & 2 \\
Killing time & 4 \\
Good physical condition & 3 \\
Self-control/being in charge of own life & 1 \\
Not being a burden to somebody else, due to the need for informal & 1 \\
$\quad$ care & 1 \\
Nostalgia/traditions & 1 \\
Peace of mind & \\
\hline
\end{tabular}

(3) Riding a bike or driving a car. For many, being able to ride a bike or a car was very important, as it allowed them to get around and to join social activities or to remain independent.

The inhibitors and facilitators for each attribute were highly personal and often resulted in a complex overview. For example, one subject wanted to be able to do her own groceries, in order to remain independent. This was made possible by a supermarket being close to her house, and the fact that she was still able to ride her bike. However, winter weather makes her afraid of falling and she then opts to stay indoors.

\section{Designing new mobility aids}

New mobility aids were developed by means of two workshops based on the mind maps and a collaboration among researchers, industrial designers, and professional caregivers.

\section{Methods}

\section{Brainstorm meeting}

A brainstorm meeting was held to co-create new ideas for mobility aids, based on the mind maps. Four researchers in health service design, two industrial designers, one community nurse, and one geriatric care manager participated. The mind maps were presented one by one to enable participants to "immerse" themselves into each of the interviewees. A presentation consisted of discussing the individual mind map and of telling the anecdotes that came with each mind map (as derived from the interview transcriptions). The brainstorm participants asked questions about the particular interviewee for clarification until they had a full grasp of the life of the elderly person. Next, they were asked to write down all ideas (products, services, or important topics) that crossed their minds on sticky notes. This was a creative activity that was not bound to any procedure. Each participant was then asked to share the ideas that they consider most valuable, after which all sticky notes were combined into clusters and prioritized.

\section{Selection of designs}

A second session was held among the eight experts of the brainstorm session, complemented by a physical and an occupational therapist, and focussed on selection of three designs to be evaluated on acceptance by the elderly. The industrial designers presented ten product ideas for mobility aids based on those ideas that were prioritized highest during the brainstorm. The industrial design company chose to work with (traditional) product designs and to focus on wheeled mobility aids.

Each product idea was discussed openly on various aspects such as safety for the elderly user, relation to the interviewees' values, and level of innovation. Together, the participants choose the three most promising ideas based on (1) the added value to mobility (predominantly judged by the care professionals), (2) the ergonomics of each product, and (3) the expected acceptance by the elderly. After this second session, redesigns of these three ideas were made, which were approved by the participants. 


\section{Results}

\section{Brainstorm meeting}

The clustered sticky notes resulted in four main areas for product ideas: (1) products that reduce fear (of falling) or increase self-assurance or safety; (2) product designs that increase acceptance and decrease the negative associations people have with mobility aids; (3) mobility aids that provide means for moving objects indoors, like a cup of tea and meals, with reduced risk of cups falling while taking obstacles such as doorsteps; and (4) mobility aids that support reaching for high or low objects, such something that fell on the floor or is stored in an overhead cupboard. The third and fourth ideas address specific functional needs of the end-users, while the first two requirements have a non-functional, general nature.

\section{Selection of designs}

The industrial designers created ten designs that focused on mobility by means of walking and biking, as these were the most important modes of transport reported by the interviewees. The healthcare providers commented on for example stability and safety by explaining about the location of the wheels with respect to the user. Based on the four main areas for product ideas from the brainstorm meeting, it was decided that three variations of the wheeled walker were the most promising designs (Figure 2):

(1) Multifunctional wheeled walker. This wheeled walker has a tray with cup holders, an anti-slip layer, and a large basket for transporting groceries. The tray can be converted to a seat with back support. This design was made to solve the problem of cups falling of the tray when crossing a doorstep with the wheeled walker.

(2) Grow-along grocery bag. This wheeled walker has three settings. First, it is a grocery bag someone can pull along. Second, wheels can be expanded that provide some support, and third, the wheels can be adjusted in such a way that the grocery bag becomes a wheeled walker with a bag in front. This design was made to ease the acceptance of wheeled walkers. At first, the person walks with a grocery bag and the shift to using a wheeled walker is smaller as the person already owns one.
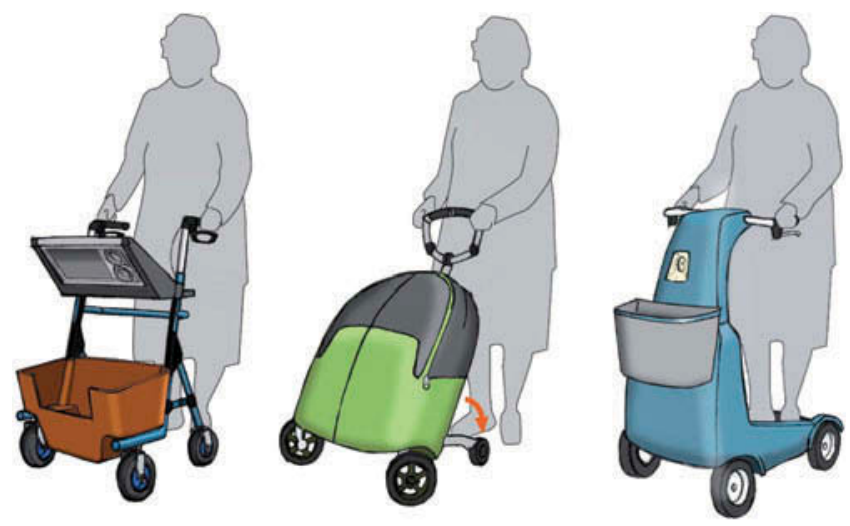

Figure 2. The three selected designs: left: the multifunctional wheeled walker, middle: the grow-along grocery bag, and right: the electric wheeled walker. For more details, see Appendix 2.
(3) Electric wheeled walker. This wheeled walker functions as a regular one, but also has a plateau which can be folded out and on which the elderly person can stand when he or she is tired. Then, the wheeled walker can move about electronically. This design was made to cater for an interviewee's fear that she would not have the energy to walk back home when she was outdoors. This prevented her from leaving her house.

\section{Gauging for acceptance}

The acceptance of mobility aids is a major concern (Bright \& Coventry, 2013). Therefore, we gauged the acceptance of the three selected designs among a sample of the target population.

\section{Methods}

\section{Participants}

Nine participants were recruited via a professional homecare organization in the Netherlands. Inclusion criteria were solitary-living, community-dwelling older adults with minimum age of 70 , without cognitive or communicational problems, and receiving a small amount of homecare. Six of the interviewees from the value-based interviews joined again.

\section{Data collection}

An interview guide with semi-structured open-ended questions was constructed, with a focus on acceptance of each design, subjective norm, coping style, and current physical activity (Appendix 3 ). The interviews were conducted at the interviewees' homes. The designs were introduced in a random order, to rule out order effects. Each of the three designs was introduced by describing it and showing its drawing (Appendix 2). Then, the interviewees were asked per design what the design reminded them of, whether they thought it would be useful, easy to use, and whether they would want to use it. Finally, we asked them whether they had experience with similar aids and what others would think if the interviewee would use this product. Subjective norm was evaluated by asking about the thoughts of friends, spouse, family, and the general practitioner of him or her using mobility aids, and whether those opinions mattered to the interviewee. Furthermore, we asked the interviewees about their coping style by presenting them with a fictitious scenario about a mobility device and asking them how they would deal with it by giving three options: use problem focused coping, stop unpleasant emotions and thoughts, and getting support from friends and family (classification by Chesney, Neilands, Chambers, Taylor, \& Folkman, 2006). Finally, current physical activity was assessed by the PASE questionnaire (Washburn et al., 1993).

\section{Data analysis}

The interviews were transcribed and two individual coders analyzed for each interviewee the interviewee's coping style and subjective norm, and for each design the user acceptance. Disagreements were discussed until agreement was reached. 
The PASE score was calculated as described in the data analysis paragraph of the first section Mapping elderly values.

\section{Results}

The interviewees (average age $81.1(\mathrm{SD}=8.1)$ ) scored low on the physical activity level (average PASE score $63(\mathrm{SD}=40)$ ). Walking was the main means of transport, although it was frequently reported that they had serious walking difficulties. Two subjects reported to be fully depended on their wheeled walker; the other subjects use it only outdoors or are not current users; see Table 3.

\section{Subjective norm and coping styles}

Most of the participants' family and friends accept the mobility device they use. Only one subject did not know her family's opinion and two subjects did not know their friend's opinion. The role of the general practitioner (GP) was reported differently. Most GPs recommended a mobility device to the interviewees. In the cases where the GP did not recommend it, the GP was also not informed about the subject using a mobility device. The importance of others (subjective norm) was considered "not important" by most subjects. Half of the subjects indicated that they preferred the coping style of "seeking help from others" and the other half choose "solving it themselves" or a combination of these two. None reported that "ignoring the problem for a while" was a coping style they would apply. When seeking help from others, the interviewees would go to family and/or health professionals (mainly to homecare nurses).

\section{Designs}

In general (All designs). Subjects were either satisfied with their current mobility device (mostly the wheeled walker) or were not using one, and not planning to start using one. Nonusers had more difficulty imaging using the product ideas than current users. And currents users were focused more on supportive functions of the walker.

Multifunctional wheeled walker. The interviewees that are current users of a wheeled walker said that this design does not replace or improve their current wheeled walker, except for one subject who felt that the additional functionalities

Table 3. Description of the participants based on demographics and the PASE scores $(n=9)$.

\begin{tabular}{|c|c|c|c|c|c|c|c|c|c|}
\hline Demographics & 11 & 12 & 13 & 14 & 15 & 16 & 17 & 18 & 19 \\
\hline Gender (M/F) & $\mathrm{F}$ & F & $\mathrm{F}$ & $\mathrm{F}$ & $\mathrm{F}$ & $\mathrm{F}$ & M & $\mathrm{F}$ & $\mathrm{F}$ \\
\hline Age (years) & 72 & 94 & 84 & 69 & 70 & 87 & 86 & 84 & 84 \\
\hline $\begin{array}{l}\text { PÁSE score (0- } \\
\text { 361) }\end{array}$ & 25 & n.a. & 53 & 123 & 91 & 31 & 9 & 50 & 118 \\
\hline Where they live ${ }^{a}$ & V & V & C & V & V & V & C & C & C \\
\hline $\begin{array}{l}\text { Transportation } \\
\text { means }^{\mathrm{b}}\end{array}$ & & $\mathrm{T}$ & $\mathrm{B}, \mathrm{Cr}$ & Sc & & & Sc & EB & PT, T \\
\hline Mobility aids ${ }^{c}$ & WW & $\begin{array}{l}\mathrm{Ca} \text {, } \\
\text { WW }\end{array}$ & $W^{*}$ & WW & WW & $\begin{array}{l}\mathrm{Ca} \text {, } \\
\text { WW }\end{array}$ & WW & $W^{*}$ & $W^{*}$ \\
\hline
\end{tabular}

Notes. n.a. $=$ subject was too tired to finish the PASE.

${ }^{\mathrm{a}} \mathrm{C}=$ city, $\mathrm{V}=$ village.

${ }^{\mathrm{b}} \mathrm{B}=$ bike, $\mathrm{EB}=\mathrm{e}$-bike, $\mathrm{Cr}=$ car, $\mathrm{Sc}=$ scootmobile, $\mathrm{PT}=$ public transport, $\mathrm{T}=$ taxi. ${ }^{c} \mathrm{Ca}=$ cane, $\mathrm{WW}=$ wheeled walker (rollator).

*Owned but not used. such as the large basket, and cushioned seat would help her in daily life. The two subjects that were not current users remarked that they would only accept a wheeled walker alike the given design, when their walking ability worsens. They predominantly reported barriers being related to the stigma of mobility aids, while the current users of wheeled walkers were mainly focused on functionality of the design.

Grow-along grocery bag. This device was not accepted as a device that the subjects would like to use, and it did not provide any added value over their current wheeled walker. Subjects expected that the shopper cannot provide sufficient balance support. And the most dominant feature of this design, the ability to store more goods (e.g., groceries), is not needed by most subjects, either because they do not need that much groceries or the bulk of their groceries are done by others. However, the participants found that its appearance reduced the stigma of a mobility device.

Electric wheeled walker. The electric walker was also not accepted as a device that would be used by the interviewees. The electric walking support was perceived as being difficult to operate and the platform is not an added value for situations in which one is tired. Standing is tiring as it requires balance and effort, and this worsens when already being tired. Subjects required a seat instead. Only this design triggered questions regarding corresponding services such as driving lessons, maintenance and range of the battery. Finally, most subjects said that it had a nice, appealing look, and that they would like to be seen with it.

\section{Discussion}

The value-based approach towards determining what matters most in the lives of solitary-living, community-dwelling elderly resulted in a very wide range of values, how people live by these values, and what hampers and helps them in fulfilling these values. The identified values relate to variables associated with life satisfaction such as quality of social network and internal locus of control (Berg, Hassing, McClearn, \& Johansson, 2006). The level on which these terms describe the things people strive for in life are alike. This suggests that the value-based approach as applied in this study is a suitable means to get an in-depth insight into the lives of a group of people, and to elicit the problems that hinder them in fulfilling their life goals. This information can be valuable for inspiring new product designs that appeal to the target population's needs and wishes, and therefore have a high chance of success. We see no reason why this approach would not yield the same results when applied to other target groups with specific needs. Value-based research can therefore open up new lines of thinking for health product and service design and can be easily integrated into a user- or human-centered design process, as it mainly entails the integration of questions or exercises aimed at eliciting life values into activities that are often used to guide end-user involvement, such as interviews, focus groups, and co-design sessions.

Given the positive experiences we gained by using a valuebased approach for mapping what matters most in terms of 
mobility for the elderly, it was disappointing that the product designs that resulted from the brainstorm were not accepted by potential end-users. We see two probable explanations for this paradox: first the translation from mind maps into designs, and second, the narrow scope that was applied on product design only.

When looking back, we think that the translation from mind map into design has not been done successfully. There is no "set" method for conducting such a brainstorm session. It was difficult to cram all the insights that were generated by the interviews into the limited time of the brainstorm session and this may make it difficult to come up with designs that appeal to important values while taking into account the myriad of barriers and facilitators described in the mind maps.

Second, we think that the focus of the design company on products (wheeled walkers) rather than product-service solutions might have created a mismatch with the original values (Wildevuur et al., 2013). The actual needs are often of a nonmaterialistic nature, like the need for being somewhere or the need for information, for which a single product is not always the best answer. A solution here is to shift the design of mobility aids to product service systems. Such systems are a combination of products and services for fulfilling a need (or value) and provide end-users with solutions of higher quality. New designs should provide an added value, substantially greater than the subjects' current mobility aids, or the ones they know. In the design cycle itself, thinking in product service systems tremendously increases the number of new product (combinations) that are imaginable (Mont, 2002). For example, when looking at the mind maps in this way, the following product-service system could be envisioned. One interviewee told us that she did not make use of the taxi as much as she would like to, due to different taxi services available and the different restrictions each service had. Some services required a transcription, some services waited for you when you visited the hospital, some were reimbursed by the health insurer, and the different services each had a different maximum amount of kilometers they would ride. An information kiosk at a central place in the neighborhood, or a website, with a wizard could help this person by determining which taxi service is most suitable for each trip. Then, it can provide an advice for a service and reserve a taxi for the person at the moment he or she wants to make the trip. Such a "taxi-wizard" would cater for the value independency and increase mobility by providing a service rather than a product.

Finally, from the second set of interviews it became clear that subjects were either satisfied with their current mobility device (mostly the wheeled walker) or were not using one, and not planning to start using one. This is in line with findings from others, such as Hedberg-Kristensson et al. (2007, p. 18), describing that "for participants who accepted that they had to use mobility aids, positive feelings such as increased independence, security and confidence had been generated," while non-acceptance was related to the "experience of realizing the need for mobility assistance causing feelings of depression [...]. Participants spoke of thresholds to overcome before starting to use mobility aids. This is in line with our findings, as we clearly see that the participants that were current users were more focussed on functions supporting their independence, security and confidence in using the mobility device, than the non-users that already had difficulty imaging using the product ideas. The results from our interviews did not suggest a relation between subjective norm and coping style on the one hand, and the acceptance of mobility aids, on the other hand.

The introductory section identified that the aim of this study was to demonstrate how value-based design can contribute to the design of mobility aids that address real human needs. Our reflection on the design process suggests that value-based design has great potential for maximizing the fit between end users' lives and context. We also determined that product service design thinking should supersede device thinking in design mobility aids for the elderly. Future research should determine how insights into the values of older adults' lives should be translated into design in an empirical manner.

\section{Limitations}

The number of persons that were interviewed (10 and 9) is too small for making generalizable statements. This is also true for having the views of only one male subject in each interview session. However, for the case of the exploration of elderly persons' values we do not see this as a problem, given the goal of our research. The interviews were held to gain deep insight into the individual lives and to identify new possibilities for new product or service designs, and by that build upon the knowledge base on mobility device use (Kylberg, Löfqvist, Phillips, \& Iwarsson, 2013). Such possibilities are most often not found in large numbers. Instead, a single story can spark the inspiration of a design team and make them design something revolutionary. For the case of gauging the acceptance of the three mobility device designs, our results should be seen as exploratory. Here, the reasons why someone accepts a device or not, are more important to us than the absolute percentages of who will or will not use such an device in the future. Related, the interview guides cannot be used as a standard for eliciting human values or for testing acceptance in relation to mobility aids, as their development was too dependent on the specific design context. We do think, however, that they can be used as a source of inspiration for other researchers and designers that work in the same or a similar field.

It may be somewhat difficult for people to comment on their intention to use a product, based on a low-fidelity prototype, such as the stories and pictures we showed to our participants (Rudd, Stern, \& Isensee, 1996). On the other hand, low-fidelity prototypes are the only affordable option to explore the usefulness of different concepts at the same moment in time (Rudd et al., 1996). For the latter reason we have decided to use these prototypes. As they were presented to the interviewees in a face-to-face situation and were accompanied by oral presentation and the possibility to pose questions about the design immediately, we think we have minimized the difficulty people may have had with imagining what the mobility aids could do for them. Nonetheless, this limitation leads to the question whether low-fidelity prototypes are only suitable for conveying the idea behind specific features (as a result of human-centered 
design) or can also convey the experience and emotional aspects of the product that are the result of value-based design. It is possible that other communication means (like animations that show the products and its use within a reallife context) do a better job here. This question can only be answered by future design research.

\section{Concluding remarks}

In this article, we have discussed our experiences with valuebased design for mobility aids for the elderly. Applying a strong focus on values (ideals or interests a [future] end user aspires to or has) when interviewing elderly about their lives resulted in a myriad of valuable insights. Although these values created large potential appealing designs, it appeared not to be a guarantee for successful product design. In order to come to a new generation of mobility aids or product service systems (Morelli, 2006) that will allow people to deal with the challenges the aging society poses, value-based design is a promising means to increase the match between user context and device. Nonetheless, researchers need to work on how to translate a value into a new design so that the elderly can benefit from ideas that align with how they want to live their lives.

\section{Acknowledgments}

We thank Trivium Meulenbelt Zorg, a Dutch homecare institute, for their input in the sessions and recruitment of the elderly participants; we thank Indes, the Netherlands, for their input in the sessions and their designs; we thank all elderly participants for their participation; and finally, we thank Kayleigh Bood, Myrthe Collard and Tessa de Visser for their contribution to the data gathering and analyses.

\section{Funding}

This research was funded within the Creative Industry Scientific Programme (CRISP). CRISP is supported by the Dutch Ministry of Education, Culture, and Science.

\section{Declaration of interest}

The authors report no conflicts of interest. The authors alone are responsible for the content and writing of the paper.

\section{ORCID}

Simone Boerema (D) http://orcid.org/0000-0002-4760-3007

Lex van Velsen (D) http://orcid.org/0000-0003-0599-8706

Miriam Vollenbroek-Hutten (D) http://orcid.org/0000-0002-8372-3022

\section{References}

Ajzen, I. (1991). The theory of planned behavior. Organizational Behavior and Human Decision Processes, 50(2), 179-211. doi:10.1016/0749-5978(91)90020-T

Berg, A. I., Hassing, L. B., McClearn, G. E., \& Johansson, B. (2006). What matters for life satisfaction in the oldest-old? Aging \& Mental Health, 10(3), 257-264. doi:10.1080/13607860500409435
Bolchini, D., Garzotto, F., \& Paolini, P. (2008). Value-driven design for infosuasive web applications. In Proceedings of the 17th International Conference on World Wide Web (pp. 745-754). New York, NY: ACM. Retrieved from http://dl.acm.org/citation.cfm?id=1367598

Braun, V., \& Clarke, V. (2006). Using thematic analysis in psychology. Qualitative Research in Psychology, 3(2), 77-101. doi:10.1191/ 1478088706qp063oa

Bright, A. K., \& Coventry, L. (2013). Assistive technology for older adults: Psychological and socio-emotional design requirements. In Proceedings of the 6th International Conference on Pervasive Technologies Related to Assistive Environments.

Britten, N. (2006). Qualitative research in health care. In Qualitative research in health care (3rd ed., pp. 12-20). Malden, MA: Blackwell Publishing.

Chesney, M. A., Neilands, T. B., Chambers, D. B., Taylor, J. M., \& Folkman, S. (2006). A validity and reliability study of the coping selfefficacy scale. British Journal of Health Psychology, 11(3), 421-437. doi:10.1348/135910705X53155

Cockton, G. (2005). A development framework for value-centred design. In Extended abstracts on Human Factors in Computing Systems (CHI'05) (pp. 1292-1295). New York, NY: ACM. Retrieved from http://dl.acm.org/citation.cfm?id=1056899

De Craen, A. J. M., Westendorp, R. G. J., Willems, C. G., Buskens, I. C. M., \& Gussekloo, J. (2006). Assistive devices and community-based services among 85-year-old community-dwelling elderly in the Netherlands: Ownership, use, and need for intervention. Disability and Rehabilitation: Assistive Technology, 1(3), 199-203. doi:10.1080/17483100612331392835

Gitlin, L. N. (1995). Why older people accept or reject assistive technology. Generations, 19(1), 41.

Gould, J. D., \& Lewis, C. (1985). Designing for usability: Key principles and what designers think. Communications of the ACM, 28(3), 300311. doi: $10.1145 / 3166.3170$

Häggblom-Kronlöf, G., \& Sonn, U. (2007). Use of assistive devices-a reality full of contradictions in elderly persons' everyday life. Disability and Rehabilitation: Assistive Technology, 2(6), 335-345. doi:10.1080/ 17483100701701672

Hedberg-Kristensson, E., Ivanoff, S. D., \& Iwarsson, S. (2007). Experiences among older persons using mobility devices. Disability and Rehabilitation: Assistive Technology, 2(1), 15-22. doi:10.1080/ 17483100600875197

Hirsch, T., Forlizzi, J., Hyder, E., Goetz, J., Stroback, J., \& Kurtz, C. (2000). The ELDer project: Social, emotional, and environmental factors in the design of eldercare technologies. In CUU ' 00 Proceedings on the 2000 Conference on Universal Usability. (pp. 72-79). New York, NY: ACM.

Kim, W. C., \& Mauborgne, R. (2004). Blue ocean strategy. Harvard Business Review, 82(10), 76-84.

Kujala, S. (2003). User involvement: A review of the benefits and challenges. Behaviour \& Information Technology, 22(1), 1-16. doi:10.1080/ 01449290301782

Kujala, S., \& Väänänen-Vainio-Mattila, K. (2009). Value of information systems and products: Understanding the users' perspective and values. Journal Information Technological Theory Applications (JITTA), 9(4), 4.

Kylberg, M., Löfqvist, C., Phillips, J., \& Iwarsson, S. (2013). Three very old men's experiences of mobility device use over time. Scandinavian Journal of Occupational Therapy, 20(5), 397-405. doi:10.3109/ 11038128.2013.779321

La Grow, S., Yeung, P., Towers, A., Alpass, F., \& Stephens, C. (2013). The impact of mobility on quality of life among older persons. Journal of Aging and Health, 25(5), 723-736. doi:10.1177/0898264313490198

Lazarus, R. S., \& Folkman, S. (1984). Stress, appraisal, and coping (p. 461). New York, NY: Springer Publishing Company.

McMillen, A.-M., \& Söderberg, S. (2002). Disabled person's experience of dependence on assistive devices. Scandinavian Journal of Occupational Therapy, 9(4), 176-183. doi:10.1080/11038120260501208

Mont, O. K. (2002). Clarifying the concept of product-service system. Journal of Cleaner Production, 10(3), 237-245. doi:10.1016/S09596526(01)00039-7 
Morelli, N. (2006). Developing new product service systems (PSS): Methodologies and operational tools. Journal of Cleaner Production, 14(17), 1495-1501. doi:10.1016/j.jclepro.2006.01.023

Resnik, L., Allen, S., Isenstadt, D., Wasserman, M., \& Iezzoni, L. (2009). Perspectives on use of mobility aids in a diverse population of seniors: Implications for intervention. Disability and Health Journal, 2(2), $77-$ 85. doi:10.1016/j.dhjo.2008.12.002

Rudd, J., Stern, K., \& Isensee, S. (1996). Low vs. high-fidelity prototyping debate. Interactions, 3(1), 76-85. doi:10.1145/223500.223514

Satariano, W. A., Guralnik, J. M., Jackson, R. J., Marottoli, R. A., Phelan, E. A., \& Prohaska, T. R. (2012). Mobility and aging: New directions for public health action. American Journal of Public Health, 102(8), 1508-1515. doi:10.2105/AJPH.2011.300631

Van Campen, C. (2011). Kwetsbare ouderen [Frail elderly] (p. 218). Den Haag, the Netherlands: Sociaal en Cultureel Planbureau.

Van Campen, C., Den Draak, M., \& Ras, M. (2011). Kwetsbaar alleen; De toename van het aantal kwetsbare alleenwonende ouderen tot 2030 [Vulnarable living alone; The expected increase of frail elderly living alone until 2030] (p. 10). Den Haag, the Netherlands: Sociaal en Cultureel Planbureau.

Van Velsen, L., Beaujean, D. J., Wentzel, J., Van Steenbergen, J. E., \& Van Gemert-Pijnen, J. E. (2015). Developing requirements for a mobile app to support citizens in dealing with ticks and tick bites via end-user profiling. Health Informatics Journal, 21(1), 24-35. doi:10.1177/1460458213496419

Van Velsen, L., Wentzel, J., \& Van Gemert-Pijnen, J. E. W. C. (2013). Designing ehealth that matters via a multidisciplinary requirements development approach. Journal of Medical Internet Research, 2(1), e21.

Washburn, R. A., Smith, K. W., Jette, A. M., \& Janney, C. A. (1993). The physical activity scale for the elderly (PASE): Development and evaluation. Journal of Clinical Epidemiology, 46(2), 153-162. doi:10.1016/ 0895-4356(93)90053-4

Wheeldon, J. P., \& Faubert, J. (2009). Framing experience: Concept maps, mind maps, and data collection in qualitative research. International Journal Qualitative Methods, 8(3), 68-83.

Wildevuur, S., Dijk, D. V., Äyväri, A., Bjerre, M., Hammer-Jakobsen, T., \& Lund, J. (2013). Connect: Design for an empathic society (p. 216). Amsterdam, the Netherlands: BIS Publishers.

\section{Appendices}

Appendix 1: Interview guide-mapping elderly values

Appendix 2: The three prototypes, including detail graphics of features and written descriptions of each design.

Appendix 3: Interview guide-gauging for acceptance 